Article

\title{
Antimicrobial Properties of Spent Hops Extracts, Flavonoids Isolated Therefrom, and Their Derivatives
}

\author{
Agnieszka Bartmańska 1,* Ewa Wałecka-Zacharska ${ }^{2}$, Tomasz Tronina ${ }^{1}$ (D), \\ Jarosław Popłoński ${ }^{1}$ (D), Sandra Sordon ${ }^{1}$, Ewa Brzezowska ${ }^{1}$, Jacek Bania ${ }^{2}$ and Ewa Huszcza ${ }^{1}$ \\ 1 Department of Chemistry, Wrocław University of Environmental and Life Sciences, Norwida 25, \\ 50-375 Wrocław, Poland; tomasz.tronina@upwr.edu.pl (T.T.); jaroslaw.poplonski@upwr.edu.pl (J.P.); \\ sandra.sordon@upwr.edu.pl (S.S.); ewa.brzezowska@upwr.edu.pl (E.B.); ewa.huszcza@upwr.edu.pl (E.H.) \\ 2 Department of Food Hygiene and Consumer Health Protection, Wrocław University of Environmental and \\ Life Sciences, Norwida 25, 50-375 Wrocław, Poland; ewa.walecka@upwr.edu.pl (E.W.-Z.); \\ jacek.bania@upwr.edu.pl (J.B.) \\ * Correspondence: agnieszka.bartmanska@upwr.edu.pl; Tel.: +48-713-205-197
}

Received: 17 July 2018; Accepted: 15 August 2018; Published: 17 August 2018

\begin{abstract}
Hop cones preparations possess a wide range of biological activities including antimicrobial properties. In this work, we evaluated the effect of various organic extracts obtained from spent hops, as well as six hops flavonoids and their twenty natural and synthetic derivatives on human and plant microbial pathogens. Methylene chloride, acetone, ethyl acetate, and methanol were used as extractants. Seven flavonoids, among them two natural $(\alpha, \beta$-dihydroxanthohumol and 8-prenylnaringenin) showed significant activity against methicillin sensitive and resistant Staphylococcus aureus and Staphylococcus epidermidis strains with the lowest MIC80 value of $0.5 \mu \mathrm{g} / \mathrm{mL}$. The crude ethyl acetate, acetone, and methanol extracts from the spent hops exhibited antifungal activity against Fusarium oxysporum, F. culmorum, and F. semitectum with the lowest MIC50 of $0.5 \mathrm{mg} / \mathrm{mL}$, while the methylene chloride extract exerted antifungal activity against Botrytis cinerea with the MIC50 of $1 \mathrm{mg} / \mathrm{mL}$. The preparation obtained after the removal of xanthohumol from the spent hops crude extracts retained up to $95 \%$ of activity. These findings suggest that various spent hops extracts may be effective agents for the control of plant pathogens of economic importance, like Botrytis cinerea and Fusarium oxysporum, while some compounds from spent hops or their derivatives may become useful for staphylococcal infections.
\end{abstract}

Keywords: spent hops; extracts; flavonoids; antibacterial activity; antifungal activity

\section{Introduction}

Numerous studies have demonstrated at the laboratory and field level that plant extracts contain diverse bioactive components that can control phytopathogens growth [1]. On the other hand, medicinal plants are a rich source of therapeutic compounds that are of use in the modern pharmaceutical industry, among them as antimicrobials against different types of microbes, including food-borne pathogens [2-4]. For ecological and economic reasons, the interest in plant waste as a source of compounds with antimicrobial activity has significantly increased recently [5,6]. Particular attention is paid to polyphenolic compounds, which, as natural factors that protect plants against infections, often become the subject of anti-infective research $[7,8]$.

The female inflorescens of hop plant (Humulus lupulus L., Cannabinaceae) are used primarily in the brewing industry to add bitterness, aroma and flavor to beer. At the beginning of human beer manufacturing, hop cones were added to provide antimicrobial properties in order to preserve the brew. These characteristics are mainly attributed to the presence of bitter acids $[9,10]$. Before use in the 
brewing industry, hops were traditionally applied for medicinal purposes, mainly for the treatment of sleeping disorders, activation of gastric functions and as stomachic, antibacterial and antifungal remedies [11]. This information indicates that the hop plant is an excellent source of compounds with antimicrobial activity.

Since large commercial brewers often apply for beer manufacturing hop extracts obtained by the extraction of cones by supercritical carbon dioxide $\left(\mathrm{CO}_{2}\right.$ extracts), it is reasonable to study the antimicrobial formulations derived from spent hops. This waste material contains a large number of valuable flavonoids that are not extracted with carbon dioxide under the conditions used for the production of common hop extracts for the brewing industry. Xanthohumol (1) is the principal flavonoid found in the hop plant which is the object of greatest interest to researchers, due to the wide spectrum of biological activity, especially broad-spectrum cancer chemopreventive ones with inhibitory mechanisms in the initiation, promotion and progression phase of carcinogenesis [12,13]. The content of xanthohumol ranges from 0.1 to $1 \%$ of the cone dry mass [14]. Except for xanthohumol, in different hop varieties, there are at least 30 other flavonoids present amounting from 10 to 100 -fold lower [15]. One of them is 8-prenylnaringenin, the most potent known plant-derived estrogen [16].

Various hops extracts, as well as individual hops compounds, are known for their antimicrobial activity. The hop bitter acids (humulones and lupulones) have shown activity against Gram-positive bacteria i.e. Lactobacillus, Streptococcus, Staphylococcus, Listeria, Clostridium and Bacillus species [17-21], gram-negative bacteria i.e. Helicobacter pylori and Brucella species [22,23] and some fungi i.e. Candida, Trichophyton, Fusarium and Mucor species [10]. This action has been attributed to the interference of a prenyl group of hop acids with the bacterial cell plasma membrane [24].

The same structural element is responsible for the antimicrobial activity of flavonoids found in hops. Prenylflavonoids exhibit antibacterial activities, especially against certain Gram-positive bacteria. Xanthohumol and 6-prenylnaringenin inhibited the growth of Staphylococcus aureus [25]. Xanthohumol also demonstrated antibacterial activity against certain oral cavity pathogens from the Streptococcus genus and pathogens caused skin inflammation and acne vulgaris from the genera of Propionibacterium, Staphylococcus, Streptococcus, and Kocuria $[18,26]$. Antifungal activity of prenylflavonoids include the ability of xanthohumol, 6- and 8-prenylnaringenin to inhibit the growth of Mucor rouxianus and the dermatophytic fungi Trichophyton spp [25].

Although the antimicrobial activity of spent hops extracts was previously examined, none of these studies investigated the impacts of different extraction solvents on the antimicrobial potential of these preparations $[27,28]$. Therefore, the purpose of this work was to evaluate the antifungal properties of four organic extracts obtained from spent hops, as well as residues of these extracts formed after the removal of xanthohumol. The antibacterial activity of extracts, hops flavonoids and its derivatives were also investigated. To our best knowledge, this is the first study on the antibacterial activity of minor hops flavonoids other than isoxanthohumol, 6- and 8-prenylnaringenin.

\section{Results}

\subsection{Production of Type I and Type II Extracts}

The extraction of the spent hops process with four organic solvents with different polarity yielded in methylene chloride $(26.01 \mathrm{~g} / \mathrm{kg})$, ethyl acetate $(38.57 \mathrm{~g} / \mathrm{kg})$, acetone $(29.82 \mathrm{~g} / \mathrm{kg})$ and methanol $(92.95 \mathrm{~g} / \mathrm{kg})$ crude extracts, described in this paper as "extracts type I". The removal of xanthohumol (1) from them using Sephadex LH-20 gel chromatography resulted in the so-called "extracts type II". All the extracts obtained were examined for the content of xanthohumol (1), and the results of these analyses are shown in Table 1. 
Table 1. The content of xanthohumol (1) achieved by HPLC in the investigated spent hops extracts type I (obtained by solvent extraction) and type II (obtained from extracts type I by the removal of $\mathbf{1}$ ).

\begin{tabular}{cccc}
\hline Extracts Type I & ${\text { Xanthohumol }[\boldsymbol{\mu g} / \mathbf{m g}]^{\mathbf{a}}}^{{ }^{2}}$ & Extracts Type II & ${\text { Xanthohumol }[\mathbf{n g} / \mathbf{m g}]^{\mathbf{a}}}^{\text {a }}$ \\
\hline methylene chloride & $51.15 \pm 0.14$ & methylene chloride & $<0.5^{\mathrm{b}}$ \\
ethyl acetate & $90.95 \pm 0.28$ & ethyl acetate & $397 \pm 15.18$ \\
acetone & $99.70 \pm 0.31$ & acetone & $278 \pm 17.95$ \\
methanol & $31.65 \pm 0.60$ & methanol & $1.5 \pm 0.91$ \\
\hline
\end{tabular}

${ }^{a}$ Data are mean \pm SD (standard deviation); ${ }^{b}$ value under the limit of quantification.

\subsection{Antibacterial Activity}

The extracts type I and II as well as the six hops flavonoids $(\mathbf{1}, \mathbf{4}, \mathbf{5}, \mathbf{7}, \mathbf{1 1}, \mathbf{1 7})$, their ten natural derivatives obtained by microbial transformation $(2,3,9,12,13,15,16,18,19,22)$, ten synthetic derivatives $(\mathbf{6}, \mathbf{8}, \mathbf{1 0}, \mathbf{1 4}, \mathbf{2 0 a}, \mathbf{2 0 b}, \mathbf{2 1}, \mathbf{2 4}, \mathbf{2 5}, \mathbf{2 6})$, and also naringenin (23) as a model compound, shown in Figure 1 were tested in vitro for their antibacterial activity.
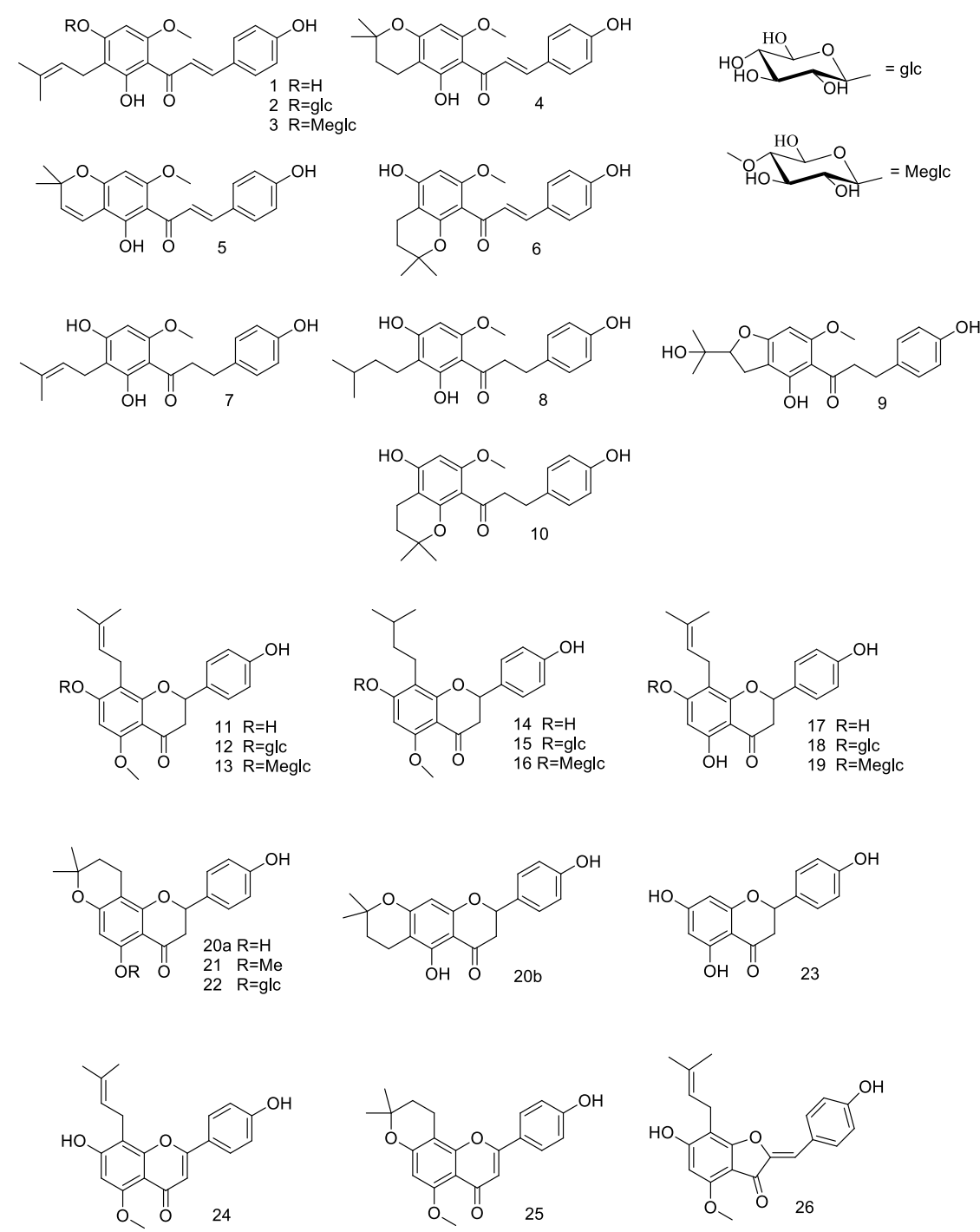

Figure 1. Hops flavonoids $(1,4,5,7,11,17)$, their derivatives obtained by microbial transformation $(2,3,9,12,13,15,16,18,19,22)$ and by chemical modifications $(6,8,10,14,20 a, 20 b, 21,24,25,26)$, and model compound naringenin (23). 
In the first approach, the agar diffusion method was used to evaluate the antibacterial activity of the crude extracts and flavonoids at the dose of $100 \mu \mathrm{g}$ and $50 \mu \mathrm{g}$ per well against Staphylococcus aureus ATCC19095, Salmonella typhimurium PCM2665 and Listeria monocytogenes ATCC7644. This preliminary assay showed that all four extracts type I and compounds 1-8, 11, 14, 17, mixture of 20a, 20b, and 26 exhibited antimicrobial activity against Staphylococcus aureus ATCC19095. For substances 7, 8, 14, 17, mixture of 20a, 20b and 26, the MIC80 values were equal to or less than $50 \mu \mathrm{g} / \mathrm{mL}$. These results are reported in Table 2 .

Table 2. Antibacterial activity of hops flavonoids and their derivatives.

\begin{tabular}{lccccccc}
\hline \multirow{2}{*}{ Microorganism } & \multicolumn{7}{c}{ MIC80 $[\boldsymbol{\mu g} / \mathbf{m L}]$} \\
\cline { 2 - 8 } & $\mathbf{7}$ & $\mathbf{8}$ & $\mathbf{1 4}$ & $\mathbf{1 7}$ & $\mathbf{2 0 a}, \mathbf{b}$ & $\mathbf{2 6}$ & Ampicillin \\
\hline S. aureus ATCC19095 (MSSA) & 12.5 & 5 & $>50$ & 50 & 12.5 & 12.5 & 2.5 \\
S. aureus ATCC43300 (MRSA) & 12.5 & 12.5 & $>50$ & 50 & 12.5 & 12.5 & $>5$ \\
S. aureus ATCC29213 (MSSA) & 12.5 & 12.5 & 50 & 25 & 12.5 & 12.5 & $>5$ \\
S. epidermidis 4s (MSSE) & 12.5 & $>50$ & 50 & 50 & 25 & 12.5 & 2.5 \\
S. epidermidis 91M (MRSE) & 25 & $>50$ & $>50$ & 50 & 25 & 25 & $>5$ \\
S. typhimurium PCM2565 & na & na & na & na & na & 50 & 5 \\
L. monocytogenes ATCC7644 & na & na & na & na & na & na & 2.5 \\
\hline
\end{tabular}

na-not active at the tested antimicrobials concentration.

\subsection{Antifungal Activity}

The antifungal activity of the spent hops extracts, both type I and type II, was evaluated at the concentration of $1 \mathrm{mg} / \mathrm{mL}$ against 7 plant pathogenic fungi: Fusarium culmorum AM10, Fusarium equiseti AM15, Fusarium semitectum AM20, Fusarium oxysporum AM21, Botrytis cinerea AM235, Penicillium purpurogenum AM80 and Mucor hiemalis AM450. The results of these experiments are presented in Table 3.

Table 3. Antifungal activity of the spent hops extracts (type I) and the residues of the spent hops extracts obtained after xanthohumol removing (type II) determined at $1 \mathrm{mg} / \mathrm{mL}$ concentration.

\begin{tabular}{ccccccccc}
\hline & \multicolumn{7}{c}{ Growth Inhibition [\%] } \\
\cline { 2 - 8 } Microorganism & \multicolumn{2}{c}{ Methylene Chloride } & \multicolumn{2}{c}{ Ethyl Ccetate } & \multicolumn{2}{c}{ Acetone } & Methanol \\
\cline { 2 - 8 } & Extract I & Extract II & Extract I & Extract II & Extract I & Extract II & Extract I & Extract II \\
\hline F. culmorum AM10 & $37.5 \pm 0.79$ & $34.2 \pm 0,40$ & $55.9 \pm 0.79$ & $41.4 \pm 0.39$ & $54.6 \pm 0.39$ & $45.2 \pm 0.79$ & $53.1 \pm 0.40$ & $41.4 \pm 1.04$ \\
F. equiseti AM15 & $35.3 \pm 1.50$ & $20.5 \pm 2.04$ & $39.7 \pm 1.50$ & $16.5 \pm 1.13$ & $44.2 \pm 0.57$ & $16.9 \pm 1.68$ & $41.2 \pm 0.98$ & $32.5 \pm 0.98$ \\
F. semitectum AM20 & $43.2 \pm 0.5$ & $15.2 \pm 1.29$ & $51.3 \pm 0.98$ & $16.2 \pm 0.98$ & $54.1 \pm 0.85$ & $24.6 \pm 0.98$ & $47.3 \pm 2.59$ & $31.6 \pm 1.76$ \\
F. oxysporum AM21 & $31.6 \pm 2.68$ & $6.1 \pm 0.45$ & $50.0 \pm 0.45$ & $7.8 \pm 0.77$ & $39.5 \pm 0.45$ & $5.1 \pm 0.77$ & $36.8 \pm 0.45$ & $4.7 \pm 1.18$ \\
B. cinerea AM235 & $50.9 \pm 1.17$ & $25.4 \pm 0.88$ & $30.9 \pm 1.17$ & $5.3 \pm 0.76$ & $36.4 \pm 0.44$ & $12.1 \pm 0.44$ & $22.4 \pm 1.93$ & $21.4 \pm 1.59$ \\
P. purpurogenum AM80 & $14.3 \pm 1.95$ & $0.0 \pm 0.98$ & $26.2 \pm 1.95$ & $9.9 \pm 0.97$ & $23.8 \pm 1.69$ & $9.1 \pm 0.97$ & $26.2 \pm 0.98$ & $1.0 \pm 0.98$ \\
M. hiemalis AM450 & $39.3 \pm 0.6$ & $0.0 \pm 1.00$ & $28.9 \pm 1.00$ & $0.0 \pm 0.50$ & $30.0 \pm 1,72$ & $0.0 \pm 0.50$ & $30.4 \pm 1,79$ & $0.0 \pm 1.00$ \\
\hline
\end{tabular}

For the four most sensitive fungi, the MIC50 values were determined (Table 4). Amphotericin B and xanthohumol (1) were used as positive control.

Table 4. The MIC50 of crude extracts against the fungal test strains.

\begin{tabular}{ccccc}
\hline \multirow{2}{*}{ Antifungals } & \multicolumn{4}{c}{ MIC50 [mg/mL] } \\
\cline { 2 - 5 } & F. culmorum AM10 & F. semitectum AM20 & F. oxysporum AM21 & B. cinerea AM235 \\
\hline methylene chloride extract I & $>1$ & $>1$ & $>1$ & 1 \\
ethyl acetate extract I & 0.5 & 1 & 1 & $>1$ \\
acetone extract I & 0.5 & 1 & $>1$ & $>1$ \\
methanol extract I & 0.5 & $>1$ & $>1$ & $>1$ \\
xanthohumol & 0.015 & 0.030 & 0.100 & 0.200 \\
amphotericin B & 0.005 & 0.005 & 0.005 & 0.005 \\
\hline
\end{tabular}




\section{Discussion}

Limited publications are available on the antimicrobial activity of spent hops extracts and only one of them concerned the effect of solvents used for extraction on antimicrobial activity [19,23,24]. Therefore, we decided to check the usefulness of crude extracts from this cheap waste material derived from the edible plant, which is also commonly used in medical applications.

Following the results of the extracts production, evidently targets methanol as the solvent of choice for the production of a large volume of crude extracts. The increase of polarity of the solvent increases the yield of the extract obtained from spent hops (methylene chloride $(26.01 \mathrm{~g} / \mathrm{kg}$ ), ethyl acetate $(38.57 \mathrm{~g} / \mathrm{kg})$, acetone $(29.82 \mathrm{~g} / \mathrm{kg})$ and methanol $(92.95 \mathrm{~g} / \mathrm{kg}))$, which is probably associated with the lower selectivity of extraction or the higher content of polar fraction in the spent hops. This is apparently the result of the supercritical $\mathrm{CO}_{2}$ extraction that selectively extracts resinous compounds for beer production, which should be more efficiently extracted with methylene chloride, than with methanol. Since the most abundant of the compounds present in the extracts was xanthohumol (1) we decided to evaluate its content in the extracts obtained, with the combination of the further removal of (extracts type II) to exclude its background activity in the extracts. The highest content of xanthohumol (1) in the spent hops preparations was observed in the crude acetone extract, less of that flavonoid contained a crude extract of ethyl acetate. However, given the efficiency and selectivity of the extraction of $\mathbf{1}$, thus a yield of the total xanthohumol (1) extracted with different solvents from spent hops, the best extractant is ethyl acetate $(3.51 \mathrm{~g} / \mathrm{kg})$, followed by acetone $(2.97 \mathrm{~g} / \mathrm{kg})$, methanol $(2.94 \mathrm{~g} / \mathrm{kg})$ and methylene chloride $(1.33 \mathrm{~g} / \mathrm{kg})$.

\subsection{Antibacterial Activity}

The antibacterial activity of the extracts and flavonoids was measured by MIC 80 determination which is defined as the concentration that inhibits the growth of $80 \%$ of organisms. Because the strain Staphylococcus aureus ATCC19095 exhibited the highest sensitivity in the agar diffusion test, four additional strains were included to the microbroth dilution assay, namely: methicillin sensitive and resistant strains of the Staphylococcus genus: S. aureus ATCC29213 (MSSA), S. aureus ATCC43300 (MRSA), S. epidermidis 91M (MRSE) and S. epidermidis 4s (MSSE, enterotoxigenic).

All the selected compounds $(7,8,14,17,20 a, 20 b, 26)$ showed antibacterial activity against the Staphylococcus species, none of them inhibited Listeria monocytogenes ATCC7644 and only aurone (26) was active against Salmonella typhimurium PCM2565 with the MIC80 value of $50 \mu \mathrm{g} / \mathrm{mL}$ (Table 2). For all the tested microorganisms, $5 \%$ dimethylsulfoxide (negative control) did not affect growth. The lowest MIC80 was observed for $\alpha, \beta, 2^{\prime}, 3^{\prime}$-tetrahydroxanthohumol (8) and S. aureus ATCC19095 (MSSA), being two times lower than the antibiotic used as the positive control (Table 2). Of special interest is the most active natural flavonoid $\alpha, \beta$-dihydroxanthohumol (7), which inhibited all the tested strains of Staphylococcus aureus and Staphylococcus epidermidis, both susceptible and resistant to methicillin. The same results were obtained for aurone (26), the synthetic derivative of xanthohumol (1) (Table 2).

By comparison of the structure of tested compounds, the antistaphylococcal activity can be related to features such as the leak of a double bond in prenyl group (chalcone 8 and flavanone 14), hydrogenated $\alpha, \beta$ double bond in chalcones (7 and 8), free C-5 hydoxyl group in flavanones (17, 20a, 20b) and the aurone skeleton (26). According to previous studies, the tested glycosides were not active [29].

The presence of the hydrophobic prenyl group in flavonoids usually increases the antimicrobial activity [30]. This relationship can be observed for 8-prenylnaringenin (17) which efficiently inhibited staphylococci, whereas naringenin (23) without the prenyl group was inactive. However, in our study, the mixture of compounds 20a, 20b with the cyclized prenyl group was also characterized by high activity against $S$. aureus and $S$. epidermidis, including methicillin resistant strains. No activity of flavanone 21, with the C-5 methoxy group in comparison to 20a, suggests that the free C-5 hydroxyl group in combination with the pyrane ring affords antimicrobial activity. Moreover, the synergism 
between 20a and 20b cannot be excluded. It has been reported that methoxy groups decrease the antibacterial activity of flavonoids against methicillin-resistant Staphylococcus aureus strains [31]. It is also in agreement with previous studies on hop flavonoids reporting that the C-5 methoxy group in isoxanthohumol (11) decreases their activity against $S$. aureus in comparison to 8-prenylnaringenin (17) [25]. In contrast to the results described in that publication, it should be noted that we found 8-prenylnaringenin (17) more active against the five Staphylococcus strains tested than xanthohumol (1), where the MIC 80 value was in all cases greater than $50 \mu \mathrm{g} / \mathrm{mL}$ (Table 2).

One of the most interesting observations is that the hydrogenated double bond in the prenyl group increases antibacterial activity, as can be observed on the example of inactive isoxanthohumol (11) and active $2^{\prime \prime}, 3^{\prime \prime}$-dihydroisoxanthohumol (14). A similar effect occurs with hydrogenated $\alpha, \beta$-double bond in the chalcone skeleton: $\alpha, \beta$-dihydroxanthohumol (7) is more active than xanthohumol (1). In turn the combination of thereof, thus hydrogenated double bond in the prenyl group and in the $\alpha, \beta$-position, in $2^{\prime \prime}, 3^{\prime \prime}, \alpha, \beta$-tetrahydroxanthohumol (8)-increases activity against $S$. aureus ATCC19095, and decreases activity against the tested strains of S. epidermidis (Table 2).

Considering the MIC80 values, particularly for methicillin-resistant Staphylococcus strains the most promising antimicrobial seems to be natural $\alpha, \beta$-dihydroxanthohumol (7). Although it is present in hops in amounts less than xanthohumol (1), the methods of the selective reduction of $\mathbf{1}$ to $\mathbf{7}$ have already been developed [32]. It is worth mentioning that 7 also exhibits slightly higher antitumor activity than $\mathbf{1}$ and chemotherapeutic drug cisplatin against the breast cancer cell line (MCF-7) [33].

\subsection{Antifungal Activity}

Recently, there is a growing interest in the research of the possible use of natural products, such as plant extracts, which may be less damaging for fungal pathogens control. The antifungal activity of plant extracts is well documented and it is postulated to be the effect of their major compounds or a synergistic effect of various compounds forming a mixture [34].

In the present study, seven field and/or storage phytopathogenic fungal strains from four different species were used to evaluate the possible activity of the spent hops extracts obtained. Apart from the production losses, the Fusarium and Aspergillus species used produce mycotoxins that pose a health hazard to humans and animals.

The type I extracts limited the growth of fungi with inhibition rates equal to or greater than $50 \%$ in seven experiments. Fungi of the genus Fusarium were more sensitive to the extracts obtained using the three more polar solvents: ethyl acetate, acetone and methanol, while Botrytis cinerea AM235 was significantly inhibited by the crude extract obtained using methylene chloride, the most non-polar extractant used (Table 3).

The most sensitive fungus was Fusarium culmorum AM10, as the growth inhibition for the crude extracts obtained with ethyl acetate, acetone and methanol was over 50\% (53.1-55.9\%). The corresponding type II extracts also showed a high inhibitory effect on Fusarium culmorum AM10, their growth inhibition ranged between $41.4-45.2 \%$. It seems that to control these fungal species the residues obtained after the recovery of xanthohumol (1) from the raw spent hops extracts can be used. This valuable compound of potential medical use was most effectively isolated with acetone and ethyl acetate (Table 1). It is noteworthy that the antifungal activity of the methanol extracts is almost equal to those obtained using ethyl acetate or acetone, wherein methanol extraction yield is up to 3 times greater.

The obtained extracts weakly inhibited the growth of Penicillium purpurogenum AM80 and Mucor hiemalis AM450. The maximal growth inhibition observed was $39.3 \%$ for M. hiemalis and methylene chloride extract I. The removal of xanthohumol (1) from the crude extracts in most trials resulted in a total lack of activity (Table 3).

By analyzing the MIC50 values determined for the four most sensitive fungi (Table 4), it can be seen that there was no direct relationship between the content of $\mathbf{1}$ in extracts and antifungal activity towards the examined fungi. Fusarium culmorum AM10 was most susceptible to crude ethyl acetate, 
acetone and methanol spent hops extracts (MIC50 $0.5 \mathrm{mg} / \mathrm{mL}$ ) and also to pure xanthohumol (1) (MIC50 $0.015 \mathrm{mg} / \mathrm{mL}$ ). Although xanthohumol (1) content is higher in the methylene chloride extract, the methanol extract was more effective, which may be due to the synergistic effects of $\mathbf{1}$ with the more polar compounds extracted by this solvent. Ethyl acetate type I extract was the most effective in the suppression of the mycelial growth of Fusarium oxysporum AM21 (MIC50 $1 \mathrm{mg} / \mathrm{mL}$ ), which was the most xanthohumol-resistant of the tested Fusarium species (MIC50 > 1mg/mL).

The most interesting area of application for the plant extracts is the inhibition of growth of the more serious plant pathogens like Botrytis cinerea and Fusarium oxysporum, which are on the 'Top 10' fungal plant pathogen list based on scientific/economic importance, published by Molecular Plant Pathology [35].

\section{Materials and Methods}

\subsection{Materials}

Extractants: methylene chloride, ethyl acetate, acetone and methanol of analytical grade were purchased from POCh (Gliwice, Poland). Acetonitrile of analytical grade were purchased from Merck (Darmstadt, Germany). Sephadex LH20, formic acid of analytical grade amphotericin B, ampicillin, Müller-Hinton agar and broth were purchased from Sigma-Aldrich (Chemie GmbH, Steinheim, Germany). The spent hops were obtained from the Production of Hop Extracts of New Chemical Syntheses Institute, Puławy, Poland by supercritical carbon dioxide extraction according to Jackowski et al. [36]. Cones (hops) of Humulus lupulus cv. 'Magnum' collected in 2015 in Lublin region (SE Poland) were used.

\subsection{Preparation of the Extracts}

Spent hops extracts type I: Four solvents with different polarities were used, i.e. methylene chloride, ethyl acetate, acetone and methanol. Spent hops ( $250 \mathrm{~g})$ were shaken with $1 \mathrm{~L}$ of each solvent for $24 \mathrm{~h}$ on a rotary shaker. Extracts were filtered with Whatman filter paper 1. Plant material was washed with a portion of $400 \mathrm{~mL}$ of solvent and collected filtrates were evaporated under vacuum at the temperature below $50{ }^{\circ} \mathrm{C}$. The residues obtained were stored at $-20^{\circ} \mathrm{C}$ for further use.

Spent hops extracts type II: spent hops extracts type I were chromatographed on a Sephadex LH-20 column using methanol as eluent. Fractions contained a majority of xanthohumol (1) were removed and the rest fractions were collected, evaporated under vacuum at the temperature below $50{ }^{\circ} \mathrm{C}$. The residues obtained were stored at $-20{ }^{\circ} \mathrm{C}$ for further use.

The all spent hops extracts were analysed for xanthohumol (1) content by HPLC on a Dionex Ultimate 3000 instrument (Thermo Fisher Scientific, Waltham, MA, United States) with a diode array detector (detection at $360 \mathrm{~nm}$ wavelength) using the analytical HPLC column Agilent ZORBAX Eclipse XDB $5 \mu \mathrm{m}(4.6 \times 250 \mathrm{~mm})$. Elution was carried out with a gradient of $40-100 \%$ solvent $(1 \%$ formic acid in $\mathrm{MeCN}$ ) in solvent $\mathrm{A}$ (aqueous $1 \%$ formic acid) in $15 \mathrm{~min}$ at the flow rate of $0.8 \mathrm{~mL} / \mathrm{min}$ after initial $2 \mathrm{~min}$ at $40 \%$ solvent $\mathrm{B}$.

\subsection{Flavonoids}

Flavonoids used in these studies were previously isolated from spent hops, or synthesized. Methods of obtaining these compounds and their spectroscopic data are described in earlier publications [32,37-43]. Xanthohumol (1) was isolated from spent hops according to the procedure described by Tronina et al. [37]. Xanthohumol 4'-O- $\beta$-D-glucopyranoside (2) and xanthohumol $4^{\prime}-O-\beta-D-\left(4^{\prime \prime \prime}-O\right.$-methyl)-glucopyranoside (3) were obtained by the biotransformation of xanthohumol (1) by fungi Absidia coerulea and Beauveria bassiana, respectively, according to Tronina et al. [38]. $1^{\prime \prime}, 2^{\prime \prime}$-Dihydroxanthohumol C (4) was the product of prenyl group cyclisation in xanthohumol (1) molecule. Reaction was catalyzed by aluminum chloride (III). Xanthohumol C (5) was obtained by cyclisation of xanthohumol (1) using 
2,3-dichloro-5,6-dicyan-1,4-benzochinone (DDQ). 1",2"-Dihydroxanthohumol K (6) was obtained by cyclisation of xanthohumol (1) using trifluoroacetic acid [39]. $\alpha, \beta$-Dihydroxanthohumol (7) was prepared from xanthohumol (1) according to the procedure of regioselective hydrogenation described by Popłoński et al. [32]. $\alpha, \beta, 2^{\prime}, 3^{\prime}$-Tetrahydroxanthohumol (8) was prepared analogously to $\alpha, \beta$-dihydroxanthohumol (7), except that the catalyst used was $10 \%$ palladium on carbon. $2^{\prime \prime}$-(2'"'-Hydroxyisopropyl)-dihydrofurano- $\left[2^{\prime \prime}, 3^{\prime \prime}: 3^{\prime}, 4^{\prime}\right]-4^{\prime}, 2$-dihydroxy-6'-methoxy- $\alpha, \beta$-dihydrochalcone (9) was obtained by the biotransformation of $\alpha, \beta$-dihydroxanthohumol (7) by fungi Aspergillus ochraceus according to the procedure described for transformation of $\mathbf{1}$ by Tronina et al. [40]. $\alpha, \beta, 1^{\prime \prime}, 2^{\prime \prime}$-Tetrahydroxanthohumol $\mathrm{K}$ (10) was prepared analogously to $\alpha, \beta$-dihydroxanthohumol (7), except that the substrate used was $1^{\prime \prime}, 2^{\prime \prime}$-dihydroxanthohumol K (6) [39]. Isoxanthohumol (11) was obtained by cyclisation of xanthohumol (1) in an alkaline environment by the method described by Bartmańska et al. [41]. Isoxanthohumol 7-O- $\beta$-D-glucopyranoside (12) and isoxanthohumol 7-O- $\beta$-D-( $4^{\prime \prime \prime}-O-$ methyl)-glucopyranoside (13) were obtained by the biotransformation of isoxanthohumol (11) by fungi Absidia coerulea and Beauveria bassiana, respectively, according to Bartmańska et al. [41]. 2" $3^{\prime \prime}$-Dihydroisoxanthohumol (14) was prepared analogously to $\alpha, \beta$-dihydroxanthohumol (7), except that the substrate used was isoxanthohumol (11). 2", $2^{\prime \prime}$-Dihydroisoxanthohumol 7-O- $\beta$-D-glucopyranoside (15) and $2^{\prime \prime}, 3^{\prime \prime}$-dihydroisoxanthohumol 7-O- $\beta$-D- $\left(4^{\prime \prime \prime}\right.$-O-methyl)-glucopyranoside (16) were obtained by the biotransformation of $2^{\prime \prime}, 3^{\prime \prime}$-dihydroisoxanthohumol (14) by fungi Absidia coerulea and Beauveria bassiana. 8-Prenylnaringenin (17) was obtained according to the procedure of demethylation of isoxanthohumol (11) described by Anioł et al. [42]. 8-Prenylnaringenin 7-O- $\beta$-D-glucopyranoside (18) and 8-prenylnaringenin 7-O- $\beta$-D- $\left(4^{\prime \prime \prime}-O-\right.$-methyl)-glucopyranoside (19) were obtained by the biotransformation of 8-prenylnaringenin (17) by fungi Absidia coerulea and Beauveria bassiana, according to Bartmańska et al. [43]. A mixture of $4^{\prime}, 5$-dihydroxy-6" $6^{\prime \prime}, 6^{\prime \prime}$-dimethyl-5" $5^{\prime \prime} 6^{\prime \prime}$-dihydro- $4^{\prime \prime} H$-pyrano $\left[2^{\prime \prime}, 3^{\prime \prime}: 7,8\right]$ flavanone (20a) and $4^{\prime}, 5$-dihydroxy-6", $6^{\prime \prime}$-dimethyl-5", $6^{\prime \prime}$-dihydro-4" $4^{\prime \prime} \mathrm{H}$-pyrano[2", $\left.3^{\prime \prime}: 6,7\right]$ flavanone $(20 \mathrm{~b})$ was the product of prenyl group cyclisation and further demethylation of isoxanthohumol (11) molecule. Reaction was catalyzed by aluminum chloride (III). 4'-Hydroxy-5-methoxy$6^{\prime \prime}, 6^{\prime \prime}$-dimethyl-5", $6^{\prime \prime}$-dihydro-4" $H$-pyrano[ $\left[2^{\prime \prime}, 3^{\prime \prime}: 7,8\right]$ flavanone (21) was the product of prenyl group cyclisation in isoxanthohumol (11) molecule in a reaction catalyzed by aluminum chloride (III). 5-O- $\beta$-D-Glucopyranosyl- $4^{\prime}$-hydroxy- $6^{\prime \prime}, 6^{\prime \prime}$-dimethyl- $5^{\prime \prime}, 6^{\prime \prime}$-dihydro-4" $H$-pyrano $\left[2^{\prime \prime}, 3^{\prime \prime}: 7,8\right]$ flavanone (22) was obtained by the biotransformation of the mixture of compounds 20a and $20 \mathrm{~b}$ by fungi Absidia coerulea39. Naringenin (23) was purchased from Sigma-Aldrich. 2,3-Dehydroisoxanthohumol (24) was a product of isoxanthohumol (11) dehydrogenation with iodine-pyridine complex [39]. 4'-Hydroxy-5-methoxy-6" $6^{\prime \prime} 6^{\prime \prime}$-dimethyl-5", $6^{\prime \prime}$-dihydro- $4^{\prime \prime} H$-pyrano[2 $\left.2^{\prime \prime}, 3^{\prime \prime}: 7,8\right]$ flavone (25) was prepared analogously to $1^{\prime \prime}, 2^{\prime \prime}$-dihydroxanthohumol $C(4)$, except that the substrate used was 2,3-dehydroisoxanthohumol (24). (Z)-6,4'-Dihydroxy-4-methoxy-7-prenylaurone (26) was prepared according to Tronina et al. [37].

\subsection{Microorganisms}

The reference bacterial strains of Staphylococcus aureus ATCC19095 (MSSA, enterotoxigenic), Staphylococcus aureus ATCC29213 (MSSA), Staphylococcus aureus ATCC43300 (MRSA), Listeria monocytogenes ATCC7644 and Salmonella typhimurium PCM2565 as well as two isolates: Staphylococcus epidermidis 91M (MRSE) and Staphylococcus epidermidis 4s (MSSE) from the collection of Department of Food Hygiene and Consumer Health Protection, Wrocław University of Environmental and Life Sciences, Poland were used. The phytopathogenic filamentous fungi used in this work, i.e., Fusarium culmorum AM10, Fusarium equiseti AM15, Fusarium semitectum AM20, Fusarium oxysporum AM21, Penicillium purpurogenum AM80, Botrytis cinerea AM235, Mucor hiemalis AM450 and Aspergillus ochraceus AM456 were obtained from the collection of the Department of Biology and Pharmaceutical Botany, Medical University of Wrocław, (Wrocław, Poland). 


\subsection{Determination of Antibacterial Activity}

The first screening of antibacterial activity was carried out using diffusion tests in Müller-Hinton agar medium, according to EUCAST recommendations (Version 1.0, 18 December 2009). The experiment was carried out on three strains: Staphylococcus aureus ATCC19095, Listeria monocytogenes ATCC7644 and Salmonella typhimurium PCM2565. Spent hops extracts and pure flavonoids were dissolved in dimethyl sulfoxide and examined at 100 and $50 \mu \mathrm{g} / \mathrm{mL}$ concentration dose. The inoculum was adjusted to the density 0.5 of a McFarland standard and $100 \mu \mathrm{L}$ was used for the plate. Then antimicrobials were aseptically dispensed into wells prepared using sterile pipette tips. The inhibition was determined after incubation at $37^{\circ} \mathrm{C}$ for $18 \mathrm{~h}$. The negative control with DMSO $(5 \%)$ and positive control with ampicillin $(2.5,5$ and $10 \mu \mathrm{g})$ were included.

MIC80 at the range from $5 \mu \mathrm{g} / \mathrm{mL}$ to $50 \mu \mathrm{g} / \mathrm{mL}$ using microbroth dilution test was determined. The panel of the tested microorganisms was expanded to include four more bacterial strains: S. aureus ATCC29213 (MSSA), S. aureus ATCC43300 (MRSA), S. epidermidis 91M (MRSE) and S. epidermidis 4s (MSSE, enterotoxigenic). Single colonies were grown in $\mathrm{MH}$ broth overnight at $37^{\circ} \mathrm{C}$. Then bacteria were diluted to $\mathrm{OD}_{600}=0.01$ and cultivated until final concentration of $6 \log \mathrm{CFU}$. The volume of $100 \mu \mathrm{L}$ of bacterial suspension was added into the well of 96-well plate containing $100 \mu \mathrm{L}$ of serially diluted antimicrobials. The negative (plain medium) and positive control (bacteria without antimicrobials) were performed. Plates were covered with lid and incubated at $37^{\circ} \mathrm{C}$ for $18 \mathrm{~h}$. The MIC endpoint was determined as the lowest concentration of the antimicrobial at which turbidity was lower or equal to $20 \%$ of the control (1:5 of control). Turbidity was read at $620 \mathrm{~nm}$. The assay was performed in triplicate with two biological repeats.

\subsection{Determination of Antifungal Activity}

The proper amounts of tested extracts were dissolved in DMSO $(0.007 \mathrm{~mL}$ of DMSO for $1 \mathrm{~mL}$ of agar medium) and added to sterilized Sabouraud agar in Petri dishes. Discs with fungal mycelia $\left(0.4 \mathrm{~cm}\right.$ in diameter) were placed on Petri dishes, which were then incubated at $27 \pm 2{ }^{\circ} \mathrm{C}$. All the extracts were tested at a concentration of $1 \mathrm{mg} / \mathrm{mL}$. For the experimental arrangements: The most active extract- the most sensitive fungus, three more concentrations were tested, which were chosen individually. Each test was repeated three times. Amphotericin B was used as reference compound. The percent of mycelia growth inhibition was estimated using as reference the control treatment (Petri dishes with Sabouraud agar medium and $0.007 \mathrm{~mL}$ of DMSO for $1 \mathrm{~mL}$ of agar) as follows: $(C-T) / C \times 100$, where $C$ is the colony diameter under the control treatment and $T$ is the colony diameter under the extract treatment.

\section{Conclusions}

Our data confirm the findings of the previous studies, which reported that hop prenylated flavonoids and extracts from hops/spent hops exhibit antistaphylococcal activity. However, this is the first study to provide data about the antimicrobial activity of minor hops flavonoids (other than isoxanthohumol, 6- and 8-prenylnaringenin) and some derivatives of xanthohumol obtained by chemical methods. In general, phytochemicals are much weaker than antibiotics, whereas the MIC80 values of some hop flavonoids determined by us were less than 2.5 times weaker against methicillin-resistant Staphylococcus aureus. These results indicate that spent hops minor flavonoids are excellent candidates for further research into their uses for food preservation as well as natural pharmaceutical products.

Taking into account the results of the present study, the ethyl acetate, acetone, and methanol crude spent hops extracts, as well as the extracts formed after the removal of xanthohumol, can be used as natural agents for crop protection against various Fusaria, while methylene chloride extract may be used against Botrytis cinerea. The high activity of these natural formulations obtained from the waste plant material in a simple extraction process makes them economically justified. 
Author Contributions: A.B. designed the research, wrote the paper; A.B., E.W.-Z., T.T., J.P., S.S. and E.B. performed the experimental works, J.B. and E.H. served as scientific advisors and contributed to the revision of the manuscript. All authors read and approved the final manuscript version.

Funding: This research was funded by Wrocław Centre of Biotechnology, programme the Leading Notional Research Centre (KNOW) for years 2014-2018.

Conflicts of Interest: The authors declare no conflict of interest.

\section{References}

1. Sharma, R.R.; Singh, D.; Singh, R. Biological control of postharvest diseases on fruits and vegetables by microbial antagonists: A review. Biol. Control. 2009, 50, 205-221. [CrossRef]

2. Cowan, M.M. Plant products as antimicrobial agents. Clin. Microbiol. Rev. 1999, 12, 564-582. [PubMed]

3. Da Cruz Cabral, L.; Virginia Fernández Pinto, V.; Patriarca, A. Application of plant derived compounds to control fungal spoilage and mycotoxin production in foods. Int. J. Food Microbiol. 2013, 166, 1-14. [CrossRef] [PubMed]

4. Friedman, M. Antibiotic-resistant bacteria: Prevalence in food and inactivation by food-compatible compounds and plant extracts. J. Agric. Food Chem. 2015, 63, 3805-3822. [CrossRef] [PubMed]

5. Vuong, Q.V. Utilisation of Bioactive Compounds from Agricultural and Food Production Waste; CRC Press, Taylor \& Francis: Boca Raton, FL, USA, 2017; pp. 1-414. ISBN 9781498741316.

6. Guil-Guerrero, J.L.; Ramos, L.; Moreno, C.; Zúñiga-Paredes, J.C.; Carlosama-Yepez, M.; Ruales, P. Antimicrobial activity of plant-food by-products: A review focusing on the tropics. Livestock Sci. 2016, 189, 32-49. [CrossRef]

7. Cushnie, T.P.T.; Lamb, A.J. Antimicrobial activity of flavonoids. Int. J. Antimicrob. Agents. 2005, 26, 343-356. [CrossRef] [PubMed]

8. Tănase, C.; Coşarcă, S.; Toma, F.; Mare, A.; Man, A.; Miklos, A.; Imre, S.; Boz, I. Antibacterial activities of beech bark (Fagus sylvatica L.) polyphenolic extract. Environ. Eng. Manag. J. 2018, 17, 877-884. [CrossRef]

9. Simpson, W.J.; Smith, A.R. Factors affecting antibacterial activity of hop compounds and their derivatives. J. Appl. Bacteriol. 1992, 72, 327-334. [CrossRef] [PubMed]

10. Mizobuchi, S.; Sato, Y. Antifungal activities of hop bitter resins and related compounds. Agric. Biol. Chem. 1985, 49, 399-403.

11. Zanoli, P.; Zavatti, M. Pharmacognostic and pharmacological profile of Humulus lupulus L. J. Ethnopharm. 2008, 116, 383-396. [CrossRef] [PubMed]

12. Miranda, C.L.; Stevens, J.F.; Helmrich, A.; Henderson, M.C.; Rodriguez, R.J.; Yang, Y.H.; Deinzer, M.L.; Barnes, D.W.; Buhler, D.R. Antiproliferative and cytotoxic effects of prenylated flavonoids from hops (Humulus lupulus) in human cancer cell lines. Food Chem. Toxicol. 1999, 37, 271-285. [CrossRef]

13. Gerhäuser, C.; Alt, A.; Heiss, E.; Gamal-Eldeen, A.; Klimo, K.; Knauft, J.; Neumann, I.; Scherf, H.R.; Frank, N.; Bartsch, H.; et al. Cancer Chemopreventive Activity of Xanthohumol, a Natural Product Derived from Hop. Mol. Cancer Ther. 2002, 1, 959-969. [PubMed]

14. Stevens, J.F.; Taylor, A.W.; Deinzer, M.L. Quantitative analysis of xanthohumol and related prenylflavonoids in hops and beer by liquid chromatography-tandem mass spectrometry. J. Chromatogr. A 1999, 832, 97-107. [CrossRef]

15. Chadwick, L.R.; Pauli, G.F.; Farnsworth, N.R. The pharmacognosy of Humulus lupulus L. (hops) with an emphasis on estrogenic properties. Phytomedicine 2006, 13, 119-131. [CrossRef] [PubMed]

16. Milligan, S.R.; Kalita, J.C.; Heyerick, A.; Rong, H.; De Cooman, L.; van Breemen, R.B. Identification of a potent phytoestrogen in hops (Humulus lupulus L.), and beer. J. Clin. Endocrinol. Metab. 1999, 84, 2249-2252. [CrossRef] [PubMed]

17. Haas, G.J.; Barsoumian, R. Antimicrobial activity of hop resins. J. Food Prot. 1994, 57, 59-61. [CrossRef]

18. Bhattacharya, S.; Virani, S.; Zavro, M.; Haas, G.J. Inhibition of Streptococcus mutans and other oral streptococci by hop (Humulus lupulus L.) constituents. Econ. Bot. 2003, 57, 118-125. [CrossRef]

19. Shen, C.; Geornaras, I.; Kendall, P.A.; Sofos, J.N. Control of Listeria monocytogenes on frankfurters by dipping in hops beta acids solutions. J. Food Prot. 2009, 72, 702-706. [CrossRef] [PubMed] 
20. Siragusa, G.R.; Haas, G.J.; Matthews, P.D.; Smith, R.J.; Buhr, R.J.; Dale, N.M.; Wise, M.G. Antimicrobial activity of lupulone against Clostridium perfringens in the chicken intestinal tract jejunum and caecum. J. Antimicrob. Chemother. 2008, 61, 853-858. [CrossRef] [PubMed]

21. Teuber, M.; Schmalreck, A.F. Membrane leakage in Bacillus subtilis 168 induced by the hop constituents lupulone, humulone, isohumulone and humulinic acid. Arch. Microbiol. 1973, 94, 159-171. [CrossRef]

22. Ohsugi, M.; Basnet, P.; Kadota, S.; Ishii, E.; Tamura, T.; Okumura, Y.; Namba, T. Antibacterial activity of traditional medicines and an active constituent lupulone from Humulus lupulus against Helicobacter. pylori. J. Trad. Med. 1997, 14, 186-191.

23. Shapouri, R.; Rahnema, M. Evaluation of antimicrobial effect of hops extracts on intramacrophages Brucella abortus and B. melitensis. Jundishapur J. Microbiol. 2011, 4, 51-58.

24. Schmalreck, A.F.; Teuber, M.; Reininger, W.; Hartl, A. Structural features determining the antibiotic potencies of natural and synthetic hop bitter resins, their precursors and derivatives. Can. J. Microbiol. 1975, 21, 205-212. [CrossRef] [PubMed]

25. Mizobuchi, S.; Sato, Y. A new flavanone with antifungal activity isolated from hops. Agric. Biol. Chem. 1984, $48,2771-2775$.

26. Yamaguchi, N.; Satoh-Yamaguchi, K.; Ono, M. In vitro evaluation of antibacterial, anticollagenase, and antioxidant activities of hop components (Humulus lupulus) addressing acne vulgaris. Phytomedicine 2009, 16, 369-376. [CrossRef] [PubMed]

27. Różalski, M.; Micota, B.; Sadowska, B.; Stochmal, A.; Jędrejek, D.; Więckowska-Szakiel, M.; Różalska, B. Antiadherent and antibiofilm activity of Humulus lupulus L. derived products: New pharmacological properties. BioMed. Res. Int. 2013, 2013, 101089. [CrossRef] [PubMed]

28. Rój, E.; Tadić, V.M.; Misić, D.; Žižović, I.; Arsić, I.; Dobrzyńska-Inger, A.; Kostrzewa, D. Supercritical carbon dioxide hops extracts with antimicrobial properties. Open Chem. 2015, 13, 157-1171. [CrossRef]

29. Barreca, D.; Bellocco, E.; Laganà, G.; Ginestra, G.; Bisignano, C. Biochemical and antimicrobial activity of phloretin and its glycosilated derivatives present in apple and kumquat. Food Chem. 2014, 160, $292-297$. [CrossRef] [PubMed]

30. Chen, X.; Mukwaya, E.; Wong, M.S.; Zhang, Y. A systematic review on biological activities of prenylated flavonoids. Pharm. Biol. 2014, 52, 655-660. [CrossRef] [PubMed]

31. Alcaráz, L.E.; Blanco, S.E.; Puig, O.N.; Tomás, F.; Ferretti, F.H. Antibacterial activity of flavonoids against methicillin-resistant Staphylococcus aureus strains. J. Theor. Biol. 2000, 205, 231-240. [CrossRef] [PubMed]

32. Popłoński, J.; Tronina, T.; Sordon, S.; Huszcza, E. Selective hydrogenation of xanthohumol to

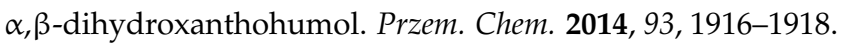

33. Tronina, T.; Bartmańska, A.; Filip-Psurska, B.; Wietrzyk, J.; Popłoński, J.; Huszcza, E. Fungal metabolites of xanthohumol with potent antiproliferative activity on human cancer cell lines in vitro. Bioorg. Med. Chem. 2013, 21, 2001-2006. [CrossRef] [PubMed]

34. Rahman, M.D.; Shovan, L.R.; Hjeljord, L.G.; Aam, B.B.; Eijsink, V.G.H.; Sørlie, M.; Tronsmo, A. Inhibition of fungal plant pathogens by synergistic action of chito-oligosaccharides and commercially available fungicides. PLoS ONE 2014, 9, E93192. [CrossRef] [PubMed]

35. Dean, R.; Van Kan, J.A.; Pretorius, Z.A.; Hammond-Kosack, K.E.; Di Pietro, A.; Spanu, P.D.; Rudd, J.J.; Dickman, M.; Kahmann, R.; Ellis, J.; et al. The Top 10 fungal pathogens in molecular plant pathology. Mol. Plant. Pathol. 2012, 13, 414-430. [CrossRef] [PubMed]

36. Jackowski, J.; Hurej, M.; Rój, E.; Popłoński, J.; Kośny, L.; Huszcza, E. Antifeedant activity of xanthohumol and supercritical carbon dioxide extract of spent hops against stored product pests. Bull. Entomol. Res. 2015, 105, 456-461. [CrossRef] [PubMed]

37. Tronina, T.; Strugała, P.; Popłoński, J.; Włoch, A.; Sordon, S.; Bartmańska, A.; Huszcza, E. The influence of glycosylation of natural and synthetic prenylated flavonoids on binding to human serum albumin and inhibition of cyclooxygenases COX-1 and COX-2. Molecules 2017, 22, 1230. [CrossRef] [PubMed]

38. Tronina, T.; Bartmańska, A.; Milczarek, M.; Wietrzyk, J.; Popłoński, J.; Rój, E.; Huszcza, E. Antioxidant and antiproliferative activity of glycosides obtained by biotransformation of xanthohumol. Bioorg. Med. Chem. Lett. 2013, 23, 1957-1960. [CrossRef] [PubMed]

39. Popłoński, J.; Turlej, E.; Sordon, S.; Tronina, T.; Bartmańska, A.; Wietrzyk, J.; Huszcza, E. Synthesis and antiproliferative activity of hops minor prenylflavonoids and new insights on prenyl group cyclization. Molecules 2018, 23, 776. [CrossRef] [PubMed] 
40. Tronina, T.; Bartmańska, A.; Popłoński, J.; Huszcza, E. Transformation of xanthohumol by Aspergillus ochraceus. J. Basic. Microbiol. 2013, 53, 1-6.

41. Artmańska, A.; Huszcza, E.; Tronina, T. Transformation of isoxanthohumol by fungi. J. Mol. Catal. B. Enzym. 2009, 61, 221-224. [CrossRef]

42. Anioł, M.; Szymańska, K.; Żołnierczyk, A. An efficient synthesis of the phytoestrogen 8-prenylnaringenin from isoxanthohumol with magnesium iodide etherate. Tetrahedron 2008, 64, 9544-9547. [CrossRef]

43. Bartmańska, A.; Tronina, T.; Huszcza, E. Transformation of 8-prenylnaringenin by Absidia coerulea and Beauveria bassiana. Bioorg. Med. Chem. Lett. 2012, 22, 6451-6453. [CrossRef] [PubMed]

Sample Availability: Samples of the compounds 1-26 are available from the authors.

(C) 2018 by the authors. Licensee MDPI, Basel, Switzerland. This article is an open access article distributed under the terms and conditions of the Creative Commons Attribution (CC BY) license (http:// creativecommons.org/licenses/by/4.0/). 